Canadian Journal of Applied Linguistics

Revue canadienne de linguistique appliquée

\title{
Error Analyses and the Cognitive or Linguistic Influences on Children's Spelling: Comparisons Between First- and Second-Language Learners
}

\author{
Gina Louise Harrison
}

Volume 24, numéro 3, automne 2021

URI : https://id.erudit.org/iderudit/1084811ar

DOI : https://doi.org/10.37213/cjal.2021.31345

Aller au sommaire du numéro

\section{Éditeur(s)}

University of New Brunswick

ISSN

1920-1818 (numérique)

Découvrir la revue

\section{Citer cet article}

Harrison, G. (2021). Error Analyses and the Cognitive or Linguistic Influences on Children's Spelling: Comparisons Between First- and Second-Language Learners. Canadian Journal of Applied Linguistics / Revue canadienne de linguistique appliquée, 24(3), 79-97. https://doi.org/10.37213/cjal.2021.31345

\section{Résumé de l'article}

Une série de mesures cognitives, linguistiques et orthographiques ont été administrées à des élèves de troisième année qui étaient des monolingues anglais (L1) ou des apprenants de langue anglaise (L2). Afin de procéder à des évaluations formatives du développement des représentations graphémiques mentales (RGM) des enfants, les erreurs orthographiques isolées ont été analysées selon trois métriques : (1) contraintes phonologiques ; (2) visuelle-orthographique ; et (3) séquences de lettres correctes. Il n'y avait pas de différences entre les groupes concernant les mesures cognitives ainsi que les mesures de précision orthographique, mais les apprenants L1 ont obtenu des scores plus élevés que les L2 dans les mesures linguistiques du vocabulaire et des connaissances syntaxiques. Des analyses des métriques d'orthographe ont indiqué que les apprenants L1 et L2 s'appuyaient davantage sur leur connaissance des règles graphophonémiques et des contraintes positionnelles de la prononciation pour l'orthographe. Cependant, la contribution de ressources sous-jacentes cognitives et linguistiques à l'orthographe différait en fonction du système de notation et du groupe linguistique. Parmi toutes les métriques d'orthographe, les prédicteurs linguistiques (vocabulaire et connaissances syntaxiques) représentaient plus de variance chez les apprenants de L1 que chez les L2. Les résultats sont discutés en relation avec la conceptualisation de l'orthographe en tant que lien intégral entre le langage oral et écrit chez le développement de l'alphabétisation.
Copyright @ Gina Louise Harrison, 2021

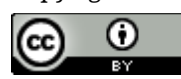

Ce document est protégé par la loi sur le droit d'auteur. L'utilisation des services d’Érudit (y compris la reproduction) est assujettie à sa politique d'utilisation que vous pouvez consulter en ligne.

https://apropos.erudit.org/fr/usagers/politique-dutilisation/ 


\title{
Error Analyses and the Cognitive or Linguistic Influences on Children's Spelling: Comparisons Between First- and Second-Language Learners
}

\author{
Gina L. Harrison \\ University of Victoria
}

\begin{abstract}
A collection of cognitive, linguistic, and spelling measures were administered to thirdgrade English L1 and L2 learners. To capture formative assessments of children's developing mental graphemic representations (MGRs), spelling errors in isolation were subjected to analysis across three metrics: (1) Phonological constrained; (2) VisualOrthographic; and (3) Correct Letter Sequences. There were no group differences on the cognitive or spelling accuracy measures, but L1 learners achieved higher scores than L2 on linguistic measures of vocabulary and syntactic knowledge. Analyses across the spelling metrics indicated that both L1 and L2 learners drew more heavily on their knowledge of graphophonemic rules and positional constraints in pronunciation for spelling. However, the contribution of underlying cognitive and linguistic resources to spelling differed as a function of scoring system and language group. Across spelling metrics, linguistic predictors (vocabulary and syntactic knowledge) accounted for more variance in L1 than L2 learners. The results are discussed in relation to conceptualization of spelling as an integral link between oral and written language in literacy development.
\end{abstract}

\section{Résumé}

Une série de mesures cognitives, linguistiques et orthographiques ont été administrées à des élèves de troisième année qui étaient des monolingues anglais (L1) ou des apprenants de langue anglaise (L2). Afin de procéder à des évaluations formatives du développement des représentations graphémiques mentales (RGM) des enfants, les erreurs orthographiques isolées ont été analysées selon trois métriques : (1) contraintes phonologiques ; (2) visuelle-orthographique; et (3) séquences de lettres correctes. Il n'y avait pas de différences entre les groupes concernant les mesures cognitives ainsi que les mesures de précision orthographique, mais les apprenants L1 ont obtenu des scores plus élevés que les L2 dans les mesures linguistiques du vocabulaire et des connaissances syntaxiques. Des analyses des métriques d'orthographe ont indiqué que les apprenants L1 et L2 s'appuyaient davantage sur leur connaissance des règles graphophonémiques et des contraintes positionnelles de la prononciation pour l'orthographe. Cependant, la contribution de ressources sous-jacentes cognitives et linguistiques à l'orthographe différait en fonction du système de notation et du groupe linguistique. Parmi toutes les métriques d'orthographe, les prédicteurs linguistiques (vocabulaire et connaissances syntaxiques) représentaient plus de variance chez les apprenants de L1 que chez les L2. Les résultats sont discutés en relation avec la conceptualisation de l'orthographe en tant que lien intégral entre le langage oral et écrit chez le développement de l'alphabétisation. 


\section{Error Analyses and the Cognitive or Linguistic Influences on Children's Spelling: Comparisons between First- and Second-Language Learners}

Spelling has been aptly described as a skill that binds language and literacy together in cognitive development with mental graphemic representations (MGRs) considered the stored lexical or sublexical representations of spoken words (Apel \& Masterson, 2001). The complex interplay between language and literacy in learning to spell is captured in influential accounts of spelling development. These accounts stress the integration of a word's unique pronunciation, orthography, and meaning (i.e., vocabulary and morphology) at the lexical and sublexical levels as instrumental in constructing the mental lexicon necessary for literacy (e.g., Bahr et al., 2009; Ehri, 1987; Treiman, 2017). In alphabetic orthographies, children's spellings move through several developmental stages marked by a growing sophistication in first capturing letter-sound connections, progressing in later stages to accurate visual-orthographic, and morphological conventions (Bourassa \& Treiman, 2001; Ehri, 1992; Moats, 1995). This development is thought to occur recursively rather than linearly as "overlapping waves" based on children's exposure to increasingly more sophisticated print and their differential use of phonological, orthographic, semantic, and morphological strategies at any given time (Rittle-Johnson \& Siegler, 1999; Varnhagen et al., 1997). Examining children's spelling errors has provided unique insight into these developmental patterns in monolinguals (L1), with a growing research interest in analyses of spelling errors in children becoming both orally proficient and literate in another language. Children's spelling errors, when examined across multiple dimensions (e.g., phonological, orthographic, morphological, etc.), provide a dynamic marker of the construction of MGRs and can elucidate particular strategies they may be drawing on to spell (Hong \& Chen, 2011). These strategies may be different between first language (L1) and second language (L2) learners. Investigating these patterns in L1 and L2 learners is a valuable methodology in studying children's spelling development in the L2, beyond what can be gleaned from only examining changes in spelling accuracy over time. Thus, one of the aims of the current study was to compare the construction of MGRs across English L1 and L2 third-graders through a multidimensional analysis of their spelling errors.

\section{Oral Language and Spelling}

L1 and L2 oral language skills, such as vocabulary and syntactic knowledge, figure prominently in conceptualizations of spelling. Children's oral vocabularies signify their store of word knowledge and facilitate the integration of a word's phonological and orthographic features in the mental lexicon for fluent retrieval (Ehri, 1992). Likewise, a rich store of semantic knowledge is particularly important when spelling homophones (i.e., words that sound the same but have different meanings) (e.g., pair/pear; Apel et al., 2004). The interconnectedness of vocabulary and spelling is also apparent from research suggesting that the most effective vocabulary interventions for young English second language (L2) learners include instructional conditions where new vocabulary words are practiced aloud and by writing their spellings (e.g., Vadasy \& Sanders, 2016). Oral syntactic knowledge represents children's facility with structural conventions in oral discourse at the sentence level and becomes more important to spelling later on in development as their lexicons expand. At this time, a more complex understanding of 
morphosyntactic conventions in spelling supersedes children's basic knowledge of graphophonemic correspondence (GPC; Scott, 2004). Indeed, with increased exposure and practice, children's MGRs become more salient, optimizing spelling accuracy and fluency (Apel \& Masterson, 2001). This view is also consistent with Trieman's (2017) Integration of Multiple Patterns (IMP) framework where learning to spell is considered dependent on a convergence of different patterns amongst "context-free" phoneme to letter associations with "context-sensitive" linguistic and orthographic patterns across phonology, morphology, and graphotactics (orthographic-specific permissible patterns, such as /qu/ in English). According to this view, children learn to spell through statistical learning based on their exposure and practice with word spellings and more readily acquire spellings where these multiple patterns converge than when they conflict. As Treiman suggests, this framework confers a more prominent role to "non-phonological knowledge" as children become more sophisticated spellers and that writing's inner function extends beyond phonology to other linguistic structures. Thus, measures of English oral vocabulary and syntactic knowledge in addition to phonological awareness (PA) were included as dependent variables in the present study. Aligning with the IMP, a key question is the extent to which these oral language variables may influence children's spelling development (as captured by their spelling errors), and whether the pattern of integration between L1 and L2 learners is similar.

\section{Predictors of Spelling Development in English L1 and L2}

To date, comparative longitudinal and cross-sectional research suggests parallels between English L1 and L2 children's trajectory of spelling development, based on measures of spelling accuracy (August \& Shanahan, 2006) and in the cognitive and linguistic processes underpinning spelling, despite persistent lags in L2 oral proficiency (see Geva, 2006 for a review; Harrison et al., 2016; Jongejan et al, 2007; Keilty \& Harrison, 2015). Children's L2 spelling skills are most strongly predicted by their PA skills in the L2 and their GPC knowledge in English as measured by word reading and pseudoword decoding tasks (Chiappe \& Siegel, 1999; Chiappe et al., 2002; Wade-Woolley \& Siegel, 1997). Spelling accuracy is also associated with rapid automatized naming (RAN), verbal working memory, and syntactic knowledge in L1 and L2 learners (Siegel, 2002), but the relative contribution of each of these processes to spelling has been found in some studies to vary between language groups. RAN is thought to capture the quality of fully-specified orthographic representations in spelling (Savage et al., 2008). While its association with spelling has been found to be stronger in beginning rather than advanced spellers (e.g., Niolaki et al., 2020), it has been found to account for more variance in younger and older children's reading and spelling accuracy in English (due to its opacity) than in other orthographies such as French, German, Hungarian, and Finnish (e.g., Moll et al., 2014). Far fewer studies have been conducted on the RAN-spelling than the RANreading connection, however, especially in young L2 learners. Verbal working memory reflects a system of short-term storage and processing activated during spelling as children hold and manipulate the sublexical and lexical units of spoken words to produce accurate spellings (Engel de Abreu \& Gathercole, 2012). In a cross-sectional study with L1 and L2 children in lower (first and second) and upper (third and fourth grades) grades, Jongejan, et al. (2007) examined the contribution of PA, RAN, verbal working memory (WM), and 
syntactic knowledge on children's spelling, as measured by spelling accuracy in isolation. Whereas PA and WM explained 56\% of the variance in spelling for L1 children in Grades 1 to 2, only PA contributed to L2 spelling (but RAN approached significance) accounting for $24 \%$ of the variance. Additionally, syntactic knowledge and verbal WM accounted for significant variance in spelling in L1 children in Grades 3 to 4 , accounting for $65 \%$ of the variance, with syntactic awareness the strongest predictor (explaining $54 \%$ of the variance). However, PA and RAN explained $40 \%$ of the variance in L2 spelling, with PA the strongest predictor (explaining $35 \%$ of the variance). Thus, PA remains a fairly stable predictor of L2 spelling across Grades 1 to 4 . Verbal WM is also important to L1 spelling in Grades 1 to 4, but oral language exerts a strong influence only in the upper grades, and only for L1, but not for L2 learners, despite the fact that both L1 and L2 learners achieve similar levels of spelling accuracy. The authors propose that English L2 children are drawing on compensatory cognitive and linguistic resources (such PA and RAN) to spell up to fourth grade, due to their less well-developed semantic and syntactic knowledge in the L2.

In another similar study that examined predictors of spelling and written expression skills in L1 and L2 learners, Harrison et al., (2016) reported comparable levels of spelling accuracy in isolation (i.e., spelling to dictation task) and in text (i.e., spelling accuracy in written paragraphs) between young L1 and L2 learners despite significant differences in oral language proficiency (syntactic knowledge and vocabulary) in favour of L1. Similar to Jongejan et als., (2007) study, language groups differed in the relative contribution of cognitive and linguistic components to spelling. For L1 learners, PA predicted spelling in isolation explaining $37 \%$ of the variance, but PA and RAN both contributed to spelling accuracy in isolation for L2, together accounting for 33\% of the variance (but PA was the strongest contributor at $28.5 \%$ ). Syntactic knowledge and verbal WM did not account for any significant variance in either model. For spelling accuracy in children's written paragraphs, PA and RAN were both significant contributors for L1 and L2 learners, (but not syntactic knowledge or verbal WM) but explained nearly twice as much variance in the accuracy of children's spelling in text for L1 (28.5\%) than for L2 (16.5\%) learners. Thus, evidence to date suggests that young L2 learners are achieving similar levels of spelling proficiency as their L1 peers, but that differences exist in the relative contribution of key cognitive and linguistic predictors. Given the important predictive role of certain cognitive and linguistic variables to spelling, a second aim of the current study was to see whether children's spelling error patterns were associated with the same cognitive and linguistic predictors irrespective of language status.

\section{Spelling Error Analysis}

The evidence to date on the cognitive and linguistic predictors of spelling among L1 and L2 learners has primarily been based on measures of spelling accuracy yielding summative information on already assembled MGRs in the L2. Studies using error analyses are limited, and only a handful have examined error patterns in relation to key cognitive and linguistic predictors of spelling. As already noted, an analysis of spelling errors provides a dynamic indicator of the progression in the formation of MGRs in children and further insight into the strategies they may be using to spell. Yeong and Rickard Liow (2011) suggested that while error analysis is labour-intensive, it affords 
several advantages over conventional accuracy only metrics including: (1) sensitivity to individual differences; (2) finer-grained analyses of cognitive-linguistic processing among linguistically diverse children, and (3) capturing spelling as a multidimensional developmental construct. Indeed, spelling error analyses reflect a valuable methodology to derive insight about oral-to-written connections at the lexical, sublexical, and supralexical levels (Hong \& Chen, 2011). Of the studies that have been conducted, cross-linguistic (L1 influences on L2) comparisons have been prominent (e.g., Bahr et al., 2015; Fashola et al., 1996; Wang \& Geva, 2003) as have comparisons on the use of linguistic conventions such as the use of vowels (e.g., Hong \& Chen, 2011; Wade-Woolley \& Siegel, 1997). Of the few studies that have compared developmental error patterns in young L1 and L2 learners, findings suggest that like spelling accuracy, English L2 children's errors also follow a similar developmental trajectory as L1 in their progression from a reliance on phonetic strategies to a more sophisticated amalgamation of phonetic and visual-orthographic approaches in L2 spelling (Geva, 2006). The similarity of developmental error profiles has been found concurrently in English L1 and L2 children in kindergarten (e.g., Keilty \& Harrison, 2015), Grades 1 and 2 (e.g., Wang \& Geva, 2003) and longitudinally in Grades 1 to 2 (e.g., Wang \& Geva, 2003). As with spelling accuracy, young children's facility with English PA is also the strongest predictor of their levels of spelling sophistication based on error analyses, regardless of language status (e.g., Keilty \& Harrison, 2015; Yeong \& Rickard Low, 2011).

A multi-system approach to spelling error analysis is to score each misspelling against phonological and orthographic criteria using a scoring scheme developed by Bruck and Waters (1988) and used by others (e.g., Harrison, 2004; Lennox \& Siegel, 1993). Such an approach also aligns well with theory, such as Ehri's (1992) Amalgamation Hypothesis and Apel and Masterson's (2001) notion of mental graphemic representations. Scores are derived for each child based on how closely their spelling attempt amalgamates a word's phonological and visual-orthographic features in forming complete MGRs. Contemporary formative spelling assessments using curriculum based measurement (CBM) employ error scoring based on the number of correct-letter sequences (CLS) apparent in children's spellings. Monitoring how many more CLS children produce in response to intervention is thought to provide valuable formative assessments of children's spelling progress than merely tracking growth of whole word accuracy (Hosp et al., 2016; Ritchey, et al., 2009). This metric was included due to its ubiquitous use in many classrooms incorporating CBM into their instructional practice, and to see if it yields any additional information beyond the phonological and visual-orthographic scoring schemes.

\section{The Present Study}

In the present study, English L1 and L2 children's misspellings were subjected to error analyses across three metrics: phonological constrained, visual-orthographic, and CLS. Although there is evidence that English L1 and L2 children's spellings contain similar patterns and developmental features (e.g., Buckwalter \& Lo, 2002; Wade-Woolley \& Siegel, 1997), whether the current study would replicate these findings and whether L1 and L2 learners would draw on the same underlying cognitive linguistic processes in becoming accurate spellers was investigated. How children's scores across each of these metrics was predicted by PA, WM, RAN, and oral language (syntactic knowledge, oral 
vocabulary) was also investigated. Although the evidence to date is sparse, it was anticipated that children's error patterns across the different metrics would be similar, indicative of comparable development despite native language differences. Due to the difference in English oral proficiency based on children's L2 status, it was also anticipated (aligned with Jongjan et al., 2007) that the relative contribution of the cognitive and linguistic predictors would vary between language groups.

\section{Participants}

\section{Method}

Third-grade children $(n=112)$ from five elementary schools in a middle-class suburban community participated in a larger study on writing achievement in English L1 and L2 children (Harrison et al., 2016). Additional analyses of children's spelling error patterns were conducted for the present study and only the measures relevant for the current analysis of spelling accuracy, error patterns, and associated cognitive linguistic predictors will be described. The L2 learners ( $n=62 ; 34$ boys, 28 girls) had an average age of 8.58 years, spoke minimal or no English upon entry to kindergarten, verified by school records, and were designated by the district as English Language Learners (ELLs). Punjabi was the L1 of the majority (90\%) of children with six students speaking a different L1 (i.e., Korean - 3 children, Malayalam, Urdu, and Spanish. All of the children had received three years of ELL instruction in a pull-out program taught by ELL specialist teachers. L1 learners ( $n=50 ; 27$ boys, 23 girls) had an average age of 8.66 years and were all native English speakers. Parents consented to their child's participation (consent forms were translated into the L1) and children also provided their consent. None of the participants had any history of neurodevelopmental disabilities, motor disorders, or sensory impairments. Children receive spelling instruction as part of the Language Arts curriculum where there is a focus on writing for different purposes (e.g., journaling, communication of information, creative writing) with evaluation based on form (mechanics), style, and content. Spelling errors are noted in children's written work, and they are expected to complete revisions and edits, including correcting mechanical errors.

\section{Measures}

All tasks were completed individually in a single one-hour session in a quiet office at the children's school. The author and trained graduate students administered and scored all of the measures in English. All of the L2 learners were proficient in English to fully understand task instructions. Since no norms are available for L2 learners on the normreferenced measures described below, raw scores were recorded. 


\section{Cognitive and Linguistic Measures}

\section{Phonological Awareness}

The Elision subtest of the Comprehensive Test of Phonological Processing (CTOPP; Wagner et al., 1999) was administered where children removed sounds from a spoken word (e.g., say 'meet' without saying/t/) to form a new word. Unlike other phonological awareness skills (e.g., rhyming, blending, segmenting), the capacity to delete phonemes is considered the most complex of skills still being consolidated in 8 to 9-yearolds (Adams, 1990; Moats \& Tolman, 2009). Testing stopped when children made three consecutive errors. Internal consistency estimates were $\alpha=.90$ and $\alpha=.91$, for L1 and L2 respectively.

\section{$R A N$}

The Rapid Letter Naming subtest of the Comprehensive Test of Phonological Processing (CTOPP) was administered to assess rapid naming. Children were instructed to read a series of lower-case letters randomly arranged into four rows and nine columns quickly and accurately. Children completed two trials and the average time to completion in seconds was recorded. Scores were converted (100 minus number of seconds) so that faster and slower performance was represented by higher and lower scores, respectively.

\section{Verbal Working Memory}

The Digit Span Backward task from the Wechsler Intelligence Scale for Children, Fourth Edition (WISC-IV; Wechsler, 2003) was administered where children repeated increasingly longer number strings in reverse order. Children completed two trials for each digit string and testing stopped when they responded incorrectly on both trials. Internal consistency estimates of $\alpha=.50$ and $\alpha=.44$ for L1 and L2, respectively

\section{Oral Receptive Vocabulary}

The Peabody Picture Vocabulary Test, 4th Edition (PPVT-4; Dunn \& Dunn, 2007) required children to match a picture to a spoken word. Testing stopped once children made 8 errors within an item block and internal consistency estimates for L1 and L2 were $\alpha=$ .90 and $\alpha=.95$, respectively.

\section{Syntactic Knowledge}

Children completed the Syntax Construction subtest of the Comprehensive Assessment of Spoken Language (CASL; Carrow-Woolfolk, 1999) where they were required to generate oral sentences in response to a picture and oral prompt using correct morphosyntactic conventions. The task was stopped when children made errors on five consecutive items and sample internal consistency estimates were $\alpha=.80$ and $\alpha=.75$ for $\mathrm{L} 1$ and L2, respectively. 


\section{Spelling Measures}

\section{Spelling Accuracy}

Children completed the Spelling subtest from the Wide Range

Achievement Test-3rd Edition (WRAT-3; Wilkinson, 1993) where they spelled single words to dictation (i.e., presented in isolation and in a sentence) that became increasingly more difficult to spell. The task was stopped when children made ten consecutive errors. Raw scores based on accuracy were recorded and internal consistency estimates were $\alpha=$ .77 and $\alpha=.86$ for L1 and L2, respectively.

\section{Spelling Error Analysis}

Children's spelling errors (the ten consecutive errors comprising test ceiling) from the WRAT-3 were scored across three metrics as shown in Table 1: phonologically constrained, visual-orthographic, and CLS. The first two approaches were based on Bruck and Waters' (1988) and Lennox and Siegel's (1993) scoring systems yielding scores for the phonological and visual-orthographic similarity of misspellings to target words. The phonologically constrained (rather than unconstrained) approach was used as high scores reflect a more sophisticated knowledge of both GPC rules and positional constraints on pronunciation, as shown in Table 1. This approach might be considered capturing children's knowledge of more "context-sensitive" phonological patterns within the IMP framework (Treiman, 2017). The third approach, as previously noted, is a common metric used in the CBM of spelling (e.g., Hosp et al., 2016) and in research (e.g., Ritchey et al., 2010). A total of 3360 words were scored across participants and metrics. All errors were scored by two raters with high inter-rater reliabilities of .88 for phonologically constrained, .94 for visual-orthographic, and .97 for CLS systems. Raters discussed all scoring discrepancies to $100 \%$ agreement. Raw scores converted to percentages were recorded across each metric for each child. Higher scores represented a greater proportion of phonological, visual-orthographic, or CLS features in misspelled words.

\section{Table 1}

Description of scoring metrics

\begin{tabular}{lll}
\hline Scoring Metric & Description & $\begin{array}{l}\text { Example Word: } \\
\text { train }\end{array}$ \\
\hline Phonologically Constrained & $\begin{array}{l}\text { The number of correct GPCs and } \\
\text { positional constraints on } \\
\text { pronunciation }\end{array}$ & $\begin{array}{l}\text { train }=4 \\
\text { trane }=4 / 4 \\
\text { tran }=3 / 4\end{array}$ \\
Visual-Orthographic & $\begin{array}{l}\text { Number of correct letters }+ \text { number } \\
\text { of correct bigrams }\end{array}$ & $\begin{array}{l}1 \text { traine }=6 / 9 \\
\text { tran }=6 / 9\end{array}$ \\
Correct Letter Sequences & $\begin{array}{l}\text { Number of correct letter sequences } \\
\text { and the space before and after }\end{array}$ & $\begin{array}{l}\text { train }=6 \\
\text { trane }=3 / 6 \\
\text { tran }=4 / 6\end{array}$ \\
& correct letter sequences & \\
\hline
\end{tabular}

Note ${ }^{1}{ }^{\text {train }}=5$ letters +4 bigrams: /tr/, /ra/, /ai/, /in/

${ }^{2}$ train $=\wedge \mathrm{t}^{\wedge} \mathrm{r}^{\wedge} \mathrm{a}^{\wedge} \mathrm{i}^{\wedge} \mathrm{n}^{\wedge}$; trane $=\wedge \mathrm{t}^{\wedge} \mathrm{r}^{\wedge}$ ane 


\section{Results}

Descriptive statistics across the cognitive, linguistic, and spelling accuracy tasks for L1 and L2 are presented in Table 2. Two between group (L1/L2) analyses of variance (ANOVA) were conducted for the cognitive (RAN, WM) and linguistic (vocabulary, syntactic knowledge, PA) measures. There were no significant differences on the RAN ( $p$ $=.31)$, WM $(p=.32)$, or PA $(p=.13)$ tasks between language groups, but L2 achieved significantly lower scores than L1 on the oral vocabulary, $F(1,110)=47.67 p<.001, \eta_{\mathrm{p}}{ }^{2}=$ .30 and syntactic knowledge measures $F(1,110)=14.28, p<.001, \eta_{\mathrm{p}}{ }^{2}=.11$.

\section{Table 2}

Descriptive statistics for cognitive, linguistic, and spelling accuracy measures

\begin{tabular}{lllllll}
\hline \multirow{2}{*}{ Measure } & \multicolumn{2}{l}{ L1 $(n=50)$} & \multicolumn{3}{l}{ L2 $(n=62)$} \\
\cline { 2 - 7 } & $M$ & $S D$ & Range & $M$ & $S D$ & Range \\
\hline CTOPP Rapid Letter Naming & 61.54 & 5.81 & $46-74$ & 62.72 & 6.47 & $44-77$ \\
WISC-IV Digit Span Backward & 5.84 & 1.26 & $4-10$ & 6.08 & 1.29 & $4-9$ \\
PPVT-4 & 148.74 & 16.47 & $117-193$ & 125.24 & 18.97 & $85-168$ \\
CASL-Syntactic Knoweldge & 32.88 & 5.34 & $18-45$ & 29.33 & 4.57 & $18-40$ \\
CTOPP-Elision & 14.96 & 4.43 & $4-19$ & 13.64 & 4.77 & $3-20$ \\
WRAT-3 Spelling & 29.0 & 4.3 & $19-38$ & 27.8 & 3.10 & $22-37$ \\
\hline
\end{tabular}

Note. CTOPP $=$ Comprehensive Test of Phonological Processing; WISC-IV $=$ Wecshler Intelligence Scale for Children $-4^{\text {th }}$ Edition; PPVT-IV $=$ Peabody Picture Vocabulary Test $-4^{\text {th }}$ Edition; CASL = Comprehensive Assessment of Spoken Language; WRAT-3 = Wide Range Achievement Test $-3^{\text {rd }}$ Edition.

There were also no significant differences between L1 and L2 for spelling accuracy $(p=.54)$. Table 3 summarizes descriptive statistics for L1 and L2 across each of the error scoring metrics. A mixed between group (L1/L2) within group error metric (phonologically constrained/CLS/visual-orthographic) repeated measures ANOVA indicated a main effect for error type $F(2,110)=1456.71 p<.001, \eta_{\mathrm{p}}{ }^{2}=.93$ and, although approaching significance $(p=.08)$, there was no language group by error metric interaction. As shown in Table 3, all children relied more heavily on phonological strategies as reflected in the higher scores on the phonologically constrained metric across language groups.

\section{Table 3}

Descriptive statistics for spelling error metrics

\begin{tabular}{lllllll}
\hline Measure & \multicolumn{2}{l}{ L1 $(n=50)$} & \multicolumn{4}{c}{ L2 $(n=62)$} \\
\cline { 2 - 7 } & $M$ & $S D$ & Range & $M$ & $S D$ & Range \\
\hline Phonologically Contrained & 73.80 & 7.91 & $53-88$ & 67.84 & 8.9 & $37-84$ \\
Visual-orthographic & 45.76 & 11.41 & $13-71$ & 41.44 & 11.53 & $15-67$ \\
Correct Letter Sequences & 51.06 & 8.88 & $29-72$ & 47.43 & 9.38 & $22-64$ \\
\hline
\end{tabular}

Next, a correlational analysis was conducted in order to examine the pattern of associations among each of the three error metrics with the cognitive and linguistic measures. The results of the correlational analysis are presented in Table 4. For L1 
learners, scores on the phonologically constrained metric correlated significantly with only the oral vocabulary $(r=.42)$ and syntactic knowledge measures $(r=.41)$; whereas WM $(r$ $=.31)$, PA $(r=.42)$, and oral vocabulary $(r=.27)$ were significantly correlated with L2 learners' phonologically constrained scores. As also shown in Table 4, children's scores on the visual-orthographic and CLS metrics were highly correlated ( $r=.92$ and $r=.95)$ for L1 and L2, respectively, suggesting that these scoring systems are tapping into a similar construct (i.e., visual-orthographic representations). However, there were differences in the pattern of associations across the cognitive and linguistic measures and these two scoring metrics among L1 and L2 learners. For the L1 group, scores on both the visualorthographic and CLS metrics were significantly correlated with WM $(r=.33)$, PA $(r=$ $.33)$, oral vocabulary $(r=.53)$, and syntactic knowledge $(r=.44)$. For the L2 group, scores on the visual-orthographic $(r=.27)$ and CLS $(r=.27)$ metrics were significantly correlated with WM only. While RAN did not significantly correlate with any of the metrics across language groups, it did approach a significant correlation $(r=.21)$ with the visualorthographic metric, and only for the L1 group.

\section{Table 4}

Correlations Among Cognitive, Linguistic, and Spelling Measures for L1/L2

\begin{tabular}{lllllllll}
\hline & 1 & 2 & 3 & 4 & 5 & 7 & 8 & 9 \\
\hline 1.RAN & 1.00 & & & & & & & \\
2.WM & $.37 / .29$ & 1.00 & & & & & & \\
3.PA & $.40 / .005$ & $.27 / .28$ & 1.00 & & & & & \\
4.Vocabulary & $.23 / .02$ & $.19 / .04$ & $.36 / .19$ & 1.00 & & & & \\
5.Syntax & $.35 / .06$ & $.29 / .02$ & $.57 / .36$ & $.50 / .34$ & 1.00 & & & \\
7.Phono. Const. & $.18 / .05$ & $.23 / .31$ & $.23 / .42$ & $.42 / .27$ & $.41 / .19$ & 1.00 & & \\
8.Visual-Ortho. & $.21 / .14$ & $.33 / .27$ & $.33 / .14$ & $.53 / .24$ & $.44 / .08$ & $.82 / .81$ & 1.00 & \\
9.CLS & $.08 / .11$ & $.29 / .27$ & $.29 / .11$ & $.44 / .21$ & $.36 / .01$ & $.77 / .82$ & $.92 / .95$ & 1.00 \\
\hline
\end{tabular}

Note. RAN = Rapid Letter Naming from the Comprehensive Test of Phonological Processing (CTOPP); WM = Digit Span Backwards from the Wechsler Intelligence Scale for Children $4^{\text {th }}$ Edition; PA $=$ Elision from the CTOPP; Vocabulary $=$ Peabody Picture Vocabulary Test $4^{\text {th }}$ Edition; Syntactic Knowledge $=$ Syntax Construction from the Comprehensive Assessment of Spoken Language; Phono . Const. $=$ Phonological-Constrained; Visual-Ortho. $=$ Visual Orthographic; CLS $=$ Correct Letter Sequences.

$p=.05$ for $r$ values at or above $.25 ; p=.01$ for $r$ values at or above .33 .

To address the final question, the relative contribution of cognitive and linguistic predictors to children's nascent MGRs (as captured by performance on the spelling error metrics) was examined. A series of hierarchical regression analyses to predict performance on each of the spelling metrics (phonologically constrained, visual-orthographic, and CLS) were run separately for L1 and L2 groups using the same set of predictor variables: PA, WM, RAN, and oral language (a composite of vocabulary and syntactic knowledge created using the unit weighted method on the mean z-scores). Guided by theory and extant empirical evidence of their contribution to spelling, PA, WM, and RAN were entered together in the first step, followed by oral language at the second step to see how much more variance would be explained by oral language. For phonologically constrained scores, as shown in Table 5, PA, WM, and RAN together explained $19.5 \%$ of the variance $(F=3.63, p=.02)$ and oral language explained an additional $8.9 \%$ of the variance $(F=$ 
$5.47, p=.02$ ) for L1 learners with both models explaining $26.8 \%$ of the variance. PA was the only significant contributor to the model (Beta $=.365, t=2.975, p=.004)$ but this significance was lost $(p=.08)$ once oral language was entered $(p=.02)$. For phonologically constrained scores, only the first model with PA, WM, and RAN was significant $(F=5.447, p=.002)$ for L2 learners explaining $22 \%$ of the variance. Oral language contributed an additional $4.5 \%$ of the variance but was not significant $(p=.06)$.

\section{Table 5}

Summary of hierarchical regression analysis of cognitive-linguistic predictors of phonologically constrained scores across language groups

\begin{tabular}{|c|c|c|c|c|c|c|c|}
\hline Language & Step & Variables & $R^{2}$ & $\operatorname{Adj} . R^{2}$ & $\begin{array}{c}R^{2} \\
\text { change }\end{array}$ & $\beta$ & $p$ \\
\hline \multirow[t]{7}{*}{$\mathrm{L} 1$} & \multirow[t]{3}{*}{1} & PA & & & & .397 & .010 \\
\hline & & WM & & & & .137 & .353 \\
\hline & & RAN & .195 & .141 & .195 & -.185 & .854 \\
\hline & \multirow[t]{4}{*}{2} & $\mathrm{PA}$ & & & & .267 & .084 \\
\hline & & WM & & & & .099 & .484 \\
\hline & & RAN & & & & -.052 & .722 \\
\hline & & $\begin{array}{l}\text { Oral } \\
\text { Language }\end{array}$ & .284 & .219 & .089 & .337 & .024 \\
\hline \multirow[t]{7}{*}{$\mathrm{L} 2$} & \multirow[t]{3}{*}{1} & PA & & & & .365 & .004 \\
\hline & & WM & & & & .212 & .103 \\
\hline & & RAN &. .223 & .182 & .223 & .004 & .997 \\
\hline & \multirow[t]{4}{*}{2} & PA & & & & .298 & .021 \\
\hline & & WM & & & & .244 & .059 \\
\hline & & RAN & & & & -.003 & .978 \\
\hline & & $\begin{array}{l}\text { Oral } \\
\text { Language }\end{array}$ & .268 & .216 & .045 & .223 & .068 \\
\hline
\end{tabular}

For the visual-orthographic scores, as shown in Table 6 for L1 learners, RAN, PA, and WM together accounted for $25.5 \%(p=.004)$ of the variance and the inclusion of oral language accounted for an additional $15.4 \%(p=.002)$ with both models explaining over $40 \%$ of the variance $(F=3.156, p=.02)$. PA was the only significant contributor to first model: $($ Beta $=.40, t=2.81, p=.007)$. However, all variance was accounted for by oral language in the final model (Beta $=.44, t=3.37, p=.002)$, PA lost significance. For the L2 learners both models explained nearly $18 \%$ of the variance, but only the first model was significant, accounting for $14.9 \%$ of the variance in visual-orthographic scores. PA was the only significant contributor to the model (Beta $=.16, t=2.15, p=.03)$. Thus, oral language appears to be a stronger contributor for L1 than L2 when children produce misspellings that look more like target spellings. 


\section{Table 6}

Summary of hierarchical regression analysis of cognitive-linguistic predictors of visualorthographic scores across language groups

\begin{tabular}{|c|c|c|c|c|c|c|c|}
\hline Language & Step & Variables & $R^{2}$ & $\operatorname{Adj} . R^{2}$ & $\begin{array}{c}R^{2} \\
\text { change }\end{array}$ & $\beta$ & $p$ \\
\hline \multirow[t]{7}{*}{ L1 } & \multirow[t]{3}{*}{1} & $\mathrm{PA}$ & & & &. .400 & .007 \\
\hline & & WM & & & & .237 & .099 \\
\hline & & RAN & .252 & .202 & .252 &.- .035 & .814 \\
\hline & \multirow[t]{4}{*}{2} & PA & & & & .229 & .102 \\
\hline & & WM & & & & .187 & .150 \\
\hline & & RAN & & & & -.066 & .620 \\
\hline & & $\begin{array}{l}\text { Oral } \\
\text { Language }\end{array}$ & .406 & .352 & .154 & .444 & .002 \\
\hline \multirow[t]{7}{*}{ L2 } & \multirow[t]{3}{*}{1} & PA & & & & .277 & .035 \\
\hline & & WM & & & & .164 & .227 \\
\hline & & RAN & .149 & .104 & .149 & .101 & .436 \\
\hline & \multirow[t]{4}{*}{2} & PA & & & & .218 & .105 \\
\hline & & WM & & & & .191 & .158 \\
\hline & & RAN & & & & .097 & .446 \\
\hline & & $\begin{array}{l}\text { Oral } \\
\text { Language }\end{array}$ & .184 & .126 & .035 & .196 & .127 \\
\hline
\end{tabular}

Finally, for the CLS scores, as shown in Table 7, only the second model which included all of the variables was significant $(F=4.20, p=.006)$ for the L1 learners accounting for $27.7 \%$ of the variance. For L2 learners, although the first model with PA, WM, and RAN explained $14.4 \%$ of the variance in CLS scores, the model did not reach significance $(p=.08)$. Oral language did not contribute any additional variance to the CLS scores achieved by L2 learners. 
Table 7

Summary of hierarchical regression analysis of cognitive-linguistic predictors of correct letter sequences across language groups

\begin{tabular}{|c|c|c|c|c|c|c|c|}
\hline Language & Step & Variables & $R^{2}$ & $\operatorname{Adj} . R^{2}$ & $\begin{array}{c}R^{2} \\
\text { change }\end{array}$ & $\beta$ & $p$ \\
\hline \multirow[t]{7}{*}{ L1 } & 1 & PA & & & & .266 & .086 \\
\hline & & WM & & & & .263 & .087 \\
\hline & & RAN & .144 & .087 & .144 & -.121 & .446 \\
\hline & 2 & PA & & & & .108 & .480 \\
\hline & & WM & & & & .217 & .131 \\
\hline & & RAN & & & & -.150 & .311 \\
\hline & & $\begin{array}{l}\text { Oral } \\
\text { Language }\end{array}$ & .277 & .211 & .133 & .412 & .007 \\
\hline \multirow[t]{7}{*}{ L2 } & 1 & $\mathrm{PA}$ & & & & .191 & .151 \\
\hline & & WM & & & & .197 & .157 \\
\hline & & RAN & .108 & .061 & .108 & .062 & .639 \\
\hline & 2 & PA & & & & .139 & .311 \\
\hline & & WM & & & & .221 & .113 \\
\hline & & RAN & & & & .059 & .653 \\
\hline & & $\begin{array}{l}\text { Oral } \\
\text { Language }\end{array}$ & .135 & .073 & .027 & .173 & .189 \\
\hline
\end{tabular}

\section{Discussion}

Although research suggests that English L2 learners' spelling (as measured by accuracy) follows a similar developmental path as English L1 learners, much less research has explored the formative assessment of spelling through the use of several error scoring metrics, and whether the same underlying cognitive and linguistic processes underpin L1 and L2 children's formation of MGRs. The present study addressed these issues. As hypothesized and replicating the results from previous studies with similar age groups (e.g., Jongejan et al., 2007; Lesaux et al., 2007), there were no differences in spelling accuracy between L1 and L2 learners. There were also no differences due to language group on the cognitive measures of verbal WM, RAN, and PA. L2 children did achieve significantly lower scores than L1 on the oral vocabulary and syntactic knowledge measures, however, also consistent with the corpus of evidence to date on persistently lower oral language skills compared to L1 children (August \& Shanahan, 2006.). These language differences continue despite the fact that the L2 children in the current sample had been simultaneously learning their L2 language and literacy skills for four years, since kindergarten, as others have also noted (e.g., Geva \& Farnia, 2011). Despite these persistent oral language differences between groups, the results of the present study indicated that all children, irrespective of L1 or L2 status, were relying on GPC knowledge in combination with orthographic rules governing pronunciation (as scored by the phonologically constrained system) in spelling. Their scores were significantly higher on this system than on the visual-orthographic or CLS scoring systems. These findings are consistent with previous research on the comparative errors between L1 and L2 learners (e.g., Wade-Woolley \& Siegel, 1997) and evidence that English L2 children are spelling 
through phonologically-based mechanisms, similar to L1 children and at the same developmental ages (Bourassa \& Treiman, 2001). The fact that the L2 children in this study have PA skills on par with their L1 peers further facilitates their drawing on this strategy when attempting to spell.

While L2 children may be relying on similar strategies and to a similar degree as L1 when spelling in the L2, the present results suggest that the influence of underlying cognitive and linguistic resources do differ as a function of scoring system and language group. Specifically, the correlational results elucidated a different pattern of associations among the error metrics and between language groups: the oral language variables were more strongly associated with each of the three spelling metrics in L1 than L2 children. Likewise, across each scoring system, less total variance was explained for L2 than for L1 learners. Based on the results from the regression analysis, the greatest proportion of variance (40\%) explained by cognitive and linguistic predictors was for the scores on the visual-orthographic system and for L1 learners. This system captured how closely children's spellings approximated the orthography of the target word. While PA was a significant contributor, it lost its significance after oral language was entered. However, for L2 children only $18 \%$ (less than half compared to L1) of the variance in their visualorthographic scores were explained by the same cognitive and linguistic predictors, and only the first model that included PA was significant.

Across the other two metrics, for L2 children, the cognitive and linguistic predictors accounted for the most variance in their scores on the phonological system $(22 \%)$ with PA the only significant contributor, whereas both PA and oral language were significant predictors for L1 children. Similarly, oral language mainly contributed to CLS scores for L1 children, but none of the cognitive or linguistic predictors were significant for L2 children. Thus, across each scoring system, less variance was explained by the cognitive and especially the linguistic predictors for L2 than for L1 learners. These findings align with the Integration of Multiple Patterns framework (Treiman, 2017) in that due to less well-developed L2 language skills (beyond phonology) compared to nativespeakers, L2 children are drawing on a different constellation of processes than their L1 counterparts in their spelling attempts.

Although comparative studies of English L1 and L2 learners have found that WM and RAN uniquely predict spelling accuracy in kindergarten through to $4^{\text {th }}$ grade (e.g., Harrison et al., 2016; Jongejan et al., 2007; Yeong \& Rickard-Liow, 2011), the current findings did not indicate these processes as significant predictors of the approaches children are using to spell. Working memory as a predictor approached significance for L2 phonologically constrained scores $(p=.059)$ in the final model which included oral language. Likewise, WM also approached significance at step 1 prior to oral language entry for the L1 group in predicting visual-orthographic and CLS scores. It is possible that lower internal consistency estimates for digit span backward also accounted for its limited influence as a predictor in the models. Future studies might include more than one WM measure across visual and verbal domains to further examine its influence on children's developing spelling accuracy. Since RAN's contribution to spelling has been assessed using spelling accuracy measures, and that conceptually it represents facility with lexical access (e.g., Savage et al., 2008; Stainthorp et al., 2013), its lack of influence in the present study may be due to the focus on spelling errors. Thus, the current study provides evidence that the RAN-spelling association may only occur when fully formed MGRs are present as 
errors provide an index of only partial representations. Similarly, associations between WM and spelling have only been studied in relation to spelling accuracy. The current results suggest that PA and oral language ostensibly supersede its contribution when spelling errors are examined.

The results also showed strong correlations among the three scoring metrics. Visual-orthographic and CLS systems were very highly correlated suggesting that they are tapping into a similar visual-orthographic construct, not surprising given the focus on coding the production of correct graphemes. Likewise, correlation coefficients between CLS and the phonological system, although of less magnitude than the visual-orthographic system, were also strong. Using slightly different metrics for two systems of phonological scoring, Ritchey et al. (2010) also reported similar strong correlations among their phonological and CLS metrics and the current results extend these findings to English L2 learners.

There are some notable limitations to the current study. First, no information was available on home literacy or the proportion of L1 or L2 language use in the home. Contemporary accounts of bilingualism view it as a continuous rather than a binary variable, and thus evaluating language along a continuum may have yielded different findings (Incerra \& McLennan, 2018). Also, the scoring systems used, while labour intensive as others have noted (Yeong \& Rickard Liow, 2011) provided breadth in analyses (visual-orthographic, letter sequencing, GPC) but did not capture depth in relation to linguistic structures. There has been an increased awareness in recent years on the important role of morphology on spelling development in L1 and in L2 learners (e.g. Bahr et al., 2015; Pacton \& Deacon, 2008) and attempts to develop appropriate scoring metrics for morphological analyses of misspellings (i.e., Bahr et al., 2012; Deacon, 2008). Extending this research to include scores for morphological approximations of children's misspellings, examining cognitive and linguistic associations, and comparisons between L1 and L2 would be an important question for further study. Similarly, concurrent results are reported here, and longitudinal analyses of the changes in error patterns over time, and in relation to underlying cognitive and linguistic processes would also be an important extension.

Overall, the results indicate that while L1 and L2 learners are achieving at similar levels for spelling accuracy and tend to be using more phonologically constrained strategies when spelling, the groups differ in the relative influence of cognitive and linguistic processes in activating these strategies, particularly when attempting to produce the correct visual representation of words. Most measures of orthographic knowledge include separate assessments of children's recognition of "real word" patterns in phonologically matched pairs of words (e.g., Olson et al., 1994) or non-words (Berninger et al., 1991). Error metrics such as CLS and visual-orthographic coding may provide an alternative by using children's own spellings to supplement or in lieu of other assessments of orthographic knowledge in research and in practice. Likewise, phonologically constrained coding provides some assessment of children's knowledge of orthographic rules that direct how speech must be represented in writing within a particular orthography. Error analysis provides a record of the kinds of strategies children may be using when attempting to spell that can ultimately be used to inform instruction, making such approaches a valuable addition to a teacher's language and literacy assessment practices. In comparative studies of L1 and L2 learners, the use of multiple error metrics within writing 
instruction provides rich insight into nascent language-literacy associations and furthers our understanding into what Apel (2011) has cogently advocated as the sixth language component, that of orthography.

Correspondence should be addressed to Gina L. Harrison Email: harrison@uvic.ca

\section{Acknowledgements}

This research was supported by a grant from the Social Sciences and Humanities Research Council of Canada. Sincere thanks to the teachers, students, and parents for participating in this study and to Kelly McManus and Lauren Goegan for their research assistance.

\section{References}

Adams, M. J. (1990). Beginning to read: Thinking and learning about print. MIT Press.

Apel, K. (2011). What is orthographic knowledge? Language, Speech, and Hearing Services in Schools, 42, 592-603. https://doi.org/10.1044/0161-1461(2011/10-0085

Apel, K., \& Masterson, J. J. (2001). Theory-guided spelling assessment and intervention: A case study. Language, Speech, and Hearing Services in the Schools, 32, 182-195. https://doi.org/10.1044/0161-1461(2001/017)

Apel, K., Masterson, J. J., \& Niessen, N. (2004). Spelling assessment frameworks. In C. A. Stone, E. R. Silliman, B. J. Ehren, \& K. Apel, (eds.), 644-660, Handbook of language and literacy: Development and Disorders. The Guilford Press.

August, D., \& Shanahan, T. (2006). Developing Literacy in Second-language Learners: Report of the National Literacy panel on Language-Minority Children and Youth. Lawrence Erlbaum \& Associates.

Bahr, R. H., Silliman, E. R., Danzak, R. L., \& Wilkinson, L. C. (2015). Bilingual spelling patterns in middle school: It is more than transfer. International Journal of Bilingual Education and Bilingualism, 18, 73-91. https://doi.org/10.1080/13670050.2013.878304

Bahr, R. H., Silliman, E. R., Berninger, V. W., \& Dow, M. (2012). Linguistic pattern analysis of misspellings of typically developing writers in Grades 1-9. Journal of Speech, Language, and Hearing Research, 55, 1587-1599. https://doi.org/10.1044/1092-4388(2012/10-0335)

Berninger, V., Yates, C., \& Lester, K. (1991). Multiple orthographic codes in reading and writing. Reading and Writing: An Interdisciplinary Journal, 3, 115-149. https://doi.org/10.1007/BF00420030

Bourassa, D., \& Treiman, R. (2001). Spelling development and disability: The importance of linguistic factors. Language, Speech, and Hearing Services in Schools, 32, $172-$ 181. https://doi.org/10.1044/0161-1461(2001/016)

Bruck, M., \& Waters, G. (1988). An analysis of the spelling errors of children who differ in their reading and spelling skills. Applied Psycholinguistics, 9, 77-92. https://doi.org/10.1017/S0142716400000461 
Buckwalter, J. K., \& Lo, Y. H. (2002). Emergent biliteracy in Chinese and English. Journal of Second Language Writing, 11(4), 269-293. https://doi.org/10.1016/S1060-3743(02)00088-7

Carrow-Woolfolk, E. (1999). Comprehensive Assessment of Spoken Language. American Guidance Service.

Chiappe, P., \& Siegel, L. S. (1999). Phonological awareness and reading acquisition in English and Punjabi-speaking Canadian children. Journal of Educational Psychology, 9, 20-28 https://doi.org/10.1037/0022-0663.91.1.20

Chiappe, P., Siegel, L. S., \& Gottardo, A. (2002). Reading-related skills of kindergarteners from diverse linguistic backgrounds. Applied Psycholinguistics, 23(1), 94-116. https://doi.org/10.1017/S0142716040200005X

Deacon, S. H. (2008). The metric matters: Determining the extent of children's knowledge of morphological spelling regularities. Developmental Science, 11(3), 396-406. https://doi.org/10.1111/j.1467-7687.2008.00684.x

Dunn, L. M., \& Dunn, D. M. (2007). Peabody Picture Vocabulary Test-4 ${ }^{\text {th }}$ Edition. American Guidance Service.

Ehri, L. C. (1992). Review and commentary: Stages of spelling development. In S. Templeton \& D. R. Bear (Eds.), Development of orthographic knowledge and the foundations of literacy: A memorial festschrift for Edmund H. Henderson (pp. 307332). Erlbaum.

Engel de Abreu, P. M. J. \& Gathercole, S. E. (2012). Executive and phonological processes in second language acquisition. Journal of Educational Psychology, 104(4), 974986. https://doi.org/10.1037/a0028390

Fashola, O. S., Drum, P. A., Mayer, R. E., \& Kang, S. J. (1996). A cognitive theory of orthographic transitioning: Predictable errors in how Spanish-speaking children spell English words. American Educational Research Journal, 33(4), 825-843. https://doi.org/10.2307/1163417

Geva, E. (2006). Second language oral proficiency and second language literacy. In D. August \& T. Shanahan (Eds.), Developing literacy in second-language learners: Report of the National Literacy Panel on language-minority children and youth (pp. 123-139). Lawrence Erlbaum Associates

Geva, E. \& Farnia, F. (2011). Developmental changes in the nature of language proficiency and reading fluency paint a more complex view of reading comprehension in ELL and EL1. Scientific Studies of Reading, 10, 31-57. https://doi.org/10.1017/S0142716411000038

Harrison, G. L. (2004). Differential use of orthographic and phonological coding strategies by students with symmetrical and asymmetrical reading and spelling skills. Canadian Journal of School Psychology, 19, 33-57.

Harrison, G. L., Goegan, L. D., Jalbert, R., McManus, K., Sinclair, K., \& Spurling, J. (2016). Predictors of spelling and writing skills in first- and second-language learners. Reading and Writing, 29, 69-89. https://doi.org/10.1007/s111145-0159580-1

Hong, S. C., \& Chen, S. H. (2011). Roles of position, stress, and proficiency in L2 children's spelling: A developmental perspective. Reading and Writing: An Interdisciplinary Journal, 24 355-385. https://doi.org/10.1007/s11145-009-9216-4 
Hosp, M. K., Hosp, J. L., \& Howell, K. W. (2016). The ABC's of CBM: A practical guide to curriculum based measurement. The Guilford Press.

Incera, S., \& McLennan, C. T. (2018). Bilingualism and age are continuous variables that influence executive function. Aging, Neuropsychology, and Cognition, 25(3), 443463. https://doi.org/10.1080/13825585.2017.1319902

Keilty, M., \& Harrison, G. L. (2015). Linguistic and literacy predictors of early spelling in first and second language learners. Canadian Journal of Applied Linguistics, 18, 87-106.

Lennox, C., Siegel, L. S. (1993). Visual and phonological spelling errors in subtypes of children with learning disabilities. Applied Psycholinguistics, 14, 473-488. https://doi.org/10.1017/S0142716400010705

Lesaux, N. K., Rupp, A. A., \& Siegel, L. S. (2007). Growth in reading skills of children from diverse linguistic backgrounds: Findings from a 5-year longitudinal study. Journal of Educational Psychology, 99, 821-834. https://doi.org/10.1037/00220663.99.4.821

Moats, L. (1995). Speech to print: Language essentials for teachers. Brookes.

Moats, L, \& Tolman, C. (2009). Essentials for teachers of reading and spelling: The speech sounds of English: Phonetics, phonology, and phoneme awareness. Sopris West.

Moll, K., Ramus, F., Bartling, J., Bruder, J., Kunze, S., Neuhoff, N., Steiftau, S., Lyytinen, H., Leppänen, K., Lohvansuu, K., Tóth, D., Honbolygó , F., Csépe, V., Bogliotti, C., Iannuzzi, S., Démonet, J. F., Longeras E., Valdois, S., George, F., ... Landerl, K. (2014).Cognitive mechanisms underlying reading and spelling development in five European orthographies. Learning and Instruction, 29 (65-77). https://doi.org/10.1016/j.learninstruc.2013.09.003

Niolaki, G. Z., Vousden, J., Tersopoulos, A. R., Taylor, L. M., Sephton, S., \& Masterson, J. (2020). Predictors of single word spelling in English speaking children: A cross sectional study. Journal of Research in Reading, 43(4), 577-596. http://doi.org/10.1111/1467-9817.12330

Olson, R., Forsberg, H., Wise, B., \& Rack, J. (1994). Measurement of word recognition, orthographic, and phonological skills. In G. R. Lyon (Ed.), Frames of reference for the assessment of learning disabilities: New views on measurement issues (pp. 243277). Paul H. Brookes Publishing Co.

Pacton, S., \& Deacon, S. H. (2008). The timing and mechanisms of children's use of morphological information in spelling: A review of evidence from English and French. Cognitive Development, 23(3), 339-359. https://doi.org/10.1016/j.cogdev.2007.09.004

Ritchey, K. D., Coker, D. L., \& McGraw, S. B. (2009). A comparison of metrics for scoring beginning spelling. Assessment for Effective Intervention, 35(2), 78-88. https://doi.org/10.1177/1534508409336087

Rittle-Johnson, B. R., \& Siegler, R. S. (1999) Learning to spell: Variability, choice, and change in children's strategy use. Child Development, 70, 332-348. https://doi.org/10.1111/1467-8624.00025

Savage, R., Pillay, V., \& Melidona, S. (2008). Rapid serial naming is a unique predictor of spelling in children. Journal of Learning Disabilities, 41, 235-250. https://doi.org/10.1177/0022219408315814 
Scott, C. M. (2004). Syntactic contributions to literacy learning. In C. A. Stone, E. R. Silliman, B. J. Ehren, \& K. Apel, (eds.), Handbook of language and literacy: development and disorders (pp. 340-362). The Guilford Press.

Siegel, L. S. (2002). Bilingualism and reading. In L. T. Verhoeven, C. Elbro, \& P. Reitsma (Eds.), Precursors of functional literacy (pp. 287-302). J. Benjamins.

Stainthorp, R., Powell, D., \& Stuart, M. (2013). The relationship between rapid naming and word spelling in English. Journal of Research in Reading, 36(4), 371-388. https://doi.org/10.1111/jrir.12002

Treiman, R. (2017). Learning to spell words: Findings, theories, and issues. Scientific Studies of Reading, 21(4), 265-276. https://doi.org/10.1080/10888438.2017.1296449

Vadasy, P. F., \& Sanders, E. A., (2016). Attention to orthographic and phonological word formsin vocabulary instruction for kindergarten English learners. Reading Psychology, 37, 833-866. https://doi.org/10.1080/02702711.2015.1116477

Varnhagen, C. K., McCallum, M., \& Burstow, M. (1997). Is children's spelling naturally stage-like? Reading and Writing: An Interdisciplinary Journal, 9, 451- 481. https://doi.org/10.1023/A:1007903330463

Wade-Woolley, L., \& Siegel, L. S. (1997). The spelling performance of ESL and native speakers of English as a function of reading skills. Reading and Writing: An Interdisciplinary Journal, 9, 387-406. https://doi.org/10.1007/978-94-017-3054-9

Wagner, R. K., Torgesen, J. K., \& Rashotte, C. A. (1999). The Comprehensive Test of Phonological Processing. ProEd.

Wang, M., \& Geva, E. (2003). Spelling acquisition of novel English phonemes in Chinese children. Reading and Writing: An Interdisciplinary Journal, 16, 325-348. https://doi.org/10.1023/A:1023661927929

Wechsler, D. (2003). Wechsler Intelligence Scale for Children (4 ${ }^{\text {th }}$ Ed.). Pearson Assessment/PsychCorp Canada.

Wilkinson, G. S., (1993). The Wide Range Achievement Test ( $3^{\text {rd }}$ ed.). Wide Range Inc.

Yeong, H. M., \& Rickard Liow, S. J. (2011). Cognitive-linguistic foundations of early spelling development in bilinguals. Journal of Educational Psychology, 103, 470488. https://doi.org/10.1037/a0022437 